\title{
“Deutsches Requiem”, de Borges. El ascetismo del sujeto fascista
}

\section{"Deutsches Requiem" by Borges. The Asceticism of the Fascist Subject}

\section{Resumen}

La crítica que ha analizado “Deutsches Requiem" (1946), de Jorge Luis Borges, se ha centrado normalmente en las incoherencias en las que incurre su protagonista y narrador, un oficial nazi: Otto Dietrich zur Linde. Enuncia explícitamente Otto que el objetivo del nazismo era la destrucción de los valores judeocristianos, pero él se muestra incapaz de pensar al margen de estos. Toda su autobiografía está contada en esa clave, la del ideal ascético, lo que tornaría incongruente su mensaje último. El ascetismo de Otto, del "sujeto fascista", no es en mi opinión una incongruencia del texto de Borges. Analizo en este artículo su naturaleza profundamente ascética, que es el resultado último del modelo de subjetividad desarrollado por la filosofía occidental.

Palabras claves

Borges, nazismo, subjetividad, ascetismo.

\begin{abstract}
The critics that have analyzed Jorge Luis Borges' "Deutsches Requiem" (1946) have usually focused on the moral inconsistencies committed by its protagonist and narrator, a Nazi officer: Otto Dietrich zur Linde. Otto explicitly states that the goal of Nazism was the destruction of Judeo-Christian values, but he is apparently unable to think outside them. All his autobiography is told through the ascetic ideal, which would make his last message incongruous. The asceticism of Otto, of the "fascist subject", is not to my view a deliberate incongruity of Borges's text. I show in this article that Otto's deeply ascetic nature is the ultimate result of the model of subjectivity developed by western philosophy.
\end{abstract}


“Deutsches Requiem” se publicó originalmente en Sur, en febrero de 1946, y posteriormente en El Aleph (1949). Es, junto con "El milagro secreto", una de las dos versiones ficcionales explícitas de Borges sobre el nazismo, con cuya ideología nacionalista y racista se había mostrado en profundo y razonado desacuerdo en varios escritos anteriores. ${ }^{1}$ El nazismo es de hecho una preocupación recurrente para Borges por esos años, y las remisiones a él son frecuentes, hasta el punto de configurar una red de referencias enciclopédicamente (des)ordenada, que autores como Emir Rodríguez Monegal (1977) y posteriormente Antonio López GómezQuiñones (2004), Edna Aizenberg (1997, 1999 y 2005) y sobre todo Annick Louis (2007) supieron desentrañar recorriendo exhaustivamente sus ensayos, reseñas, notas y artículos de prensa. La inquietud, sugerida en alguna ocasión, que podría generar un relato como 'Deutsches Requiem', casi una justificación del nazismo escrita en primera persona por un nazi, empieza a quedar neutralizada si se lee en relación al resto de textos borgeanos de la época.

En "Deutsches Requiem", Borges, que parece haber inaugurado todas las tendencias literarias del siglo XX, además de habernos enseñado a leer la literatura de los siglos anteriores, nos ofrece una de las cápsulas (auto)biográficas a las que el discurso Post-Auschwitz recurrirá con insistencia. Ahora bien, Borges decide dar la palabra al nazi, al verdugo vencido, mientras que los textos posteriores optarán, casi siempre, por dar la voz a las víctimas. Mientras se celebraban los juicios de Núremberg, el ficticio Otto Dietrich zur Linde, subdirector del no menos ficticio

${ }^{1}$ En Sur, precisamente, se habían publicado cinco artículos suyos que trataban específicamente sobre el tema: 'Una pedagogía del odio' (mayo de 1937); 'Letras alemanas, una explicación afligente' (octubre de 1938); 'Ensayo de imparcialidad' (octubre de 1939); '1941' (diciembre de 1941). 'Anotación al 23 de agosto de 1944' (octubre de 1944); 'Nota sobre la paz' (Julio de1945). Los artículos en Sur, artículos sobre la Segunda Guerra Mundial y el nazismo, son el marco textual adecuado para entender parte de las pretensiones y el sentido del relato. 
campo de concentración de Tarnowitz, ensaya su autobiografía justo después de ser sentenciado a muerte. Su objetivo no es justificarse ni implorar perdón. Hacerlo implicaría descreer de sus ideas y desvirtuar el sistema que cree haber ayudado a instaurar. Su autobiografía aspira a hacerle entender al mundo la razón de ser del nazismo, y la necesidad de su destrucción para que quede instituido un régimen de violencia global. ${ }^{2}$ Este sacrificio encontraría en Hitler a su profeta, una especie de Anticristo que se habría inmolado para que triunfara el ideal que representa.

Difícil no pensar en las 'Tres versiones de Judas', en versión incluso más pervertida. Borges ya había vertido esta idea, por cierto, en 'Anotación al 23 de agosto de 1944', donde escribió que el nazismo era una imposibilidad mental y moral, y esa era la razón, y no la aducida por Otto, por la que quería ser derrotado:

El nazismo adolece de irrealidad, como los infiernos de Erígena. Es inhabitable; los hombres solo pueden morir por él, mentir por él, matar y ensangrentar por él. Nadie, en la soledad central de su yo, puede anhelar que triunfe. Arriesgo esta conjetura. Hitler quiere ser derrotado. Hitler, de un modo ciego, colabora con los inevitables ejércitos que lo aniquilarán. (Obra completas II 106)

En todo caso, la forma, los ecos a otros textos borgeanos (aunque cambie el sentido, como en el caso que acabo de referir), el tono e incluso el mensaje de Deutsches Requiem son incómodos, aunque no es la primera vez que Borges se ocupa de hombres infames sin afán justificativo alguno. También perturba la familiaridad del lector borgeano con algunos de sus temas y estrategias narrativas habituales. Inquieta incluso el parecido entre autor y personaje. Borges debía, por tanto, ser muy cuidadoso en este relato. Su primer gesto es dar la palabra

\footnotetext{
${ }^{2}$ Algo que no es del todo descartable si tenemos en cuenta el comportamiento de los aliados durante la guerra, y después de ser derrotada Alemania, con bombardeos constantes sobre la población civil alemana. Un tema incómodo que pocos autores, entre ellos Sebald (1999), se han atrevido a tratar.
} 
decididamente al nazi: "Mi nombre es Otto Dietrich zur Linde" (Obras completas I 576). Borges evita además introducirse en este texto como personaje / narrador, evita incluso como el Borges 'moron', por ingenuo o deliberadamente torpe, del que nos habla Enrique Pezzoni (1999), y que aparece frecuentemente en su producción de la época. Borges autor y Borges personaje se desligan del cuerpo del texto.

\section{'Deutsches Requiem' ante a la crítica}

Esta preocupación por cuestiones históricas coetáneas plasmada en "Deutsches Requiem" desmentía la idea general, tempranamente propagada por Ana María Barrenechea, de que Borges era básicamente un autor de relatos fantásticos. Una idea vertida desde Argentina, pero también desde Estados Unidos. En New York Review of Books, el influyente Paul de Man (19/11/1964) trazó un retrato de Borges, "A Modern Master", como autor de laberintos y paradojas especulares muy cuidadosamente presentadas. Borges, incluso si trataba temas morales, lo hacía por su valor estético y por los recursos estilísticos que le permitían desplegar. En ese esquema general y pocas veces discutido de interpretación, que recorrió Edna Aizenberg (2005), el análisis de un relato como el que nos ocupa era frecuente y convenientemente omitido.

La referencialidad palmaria de "Deutsches Requiem", en desacuerdo con la crítica canónica del autor, y un planteamiento que podía resultar incómodo leído fuera de contexto, provocó, de hecho, que no fuera un texto especialmente comentado en el siglo XX, aunque estuviera en el corazón de la obra canónica de Borges, en El Aleph. Como dijo Rafael Gutiérrez Girardot, "en 1949, Borges publicó un cuento que fue mal interpretado y que en la literatura sobre Borges se ha mencionado tan raramente que se puede sostener que ha sido pasado por alto" (202). Afortunadamente, las tornas habían empezado a cambiar en los años noventa, y diversos críticos decidieron afrontar "Deutsches Requiem", trocando, de paso, la imagen tradicional del Borges alejado de toda referencialidad histórico- 
política, o sencillamente la del escritor conservador cuya posición ideológica es mostrarse ajeno a las ideologías.

Un artículo pionero de Yasmine-Sigride Vandorpe (1995) aplicó, siguiendo a Jaime Alazraki (verdadero precursor en la interpretación del incómodo relato), la imagen tradicional del Borges especulativo y paradójico a "Deutsches Requiem", y demostró que la abstracción filosófica y la preocupación histórica e ideológica no eran excluyentes en su obra. Parafraseando a Aizenberg ("Deutsches Requiem..." 37-38), la posibilidad de que Borges, en especial en este relato, lidiara con la relación entre filosofía y política, o sobre la filosofía como acto político y la política como acto filosófico, empezaba a entrar en el horizonte de expectativas de los comentadores borgeanos.

Empezaron a publicarse libros y artículos que profundizaban enormemente en esta línea de interpretación. ${ }^{3}$ Yo mismo pretendo sumarme a ella, y trataré de demostrar en este artículo la relación entre una determinada concepción de la subjetividad, desarrollada por la filosofía moderna sobre el presupuesto de la excepcionalidad humana, y la ideología nazi, al menos en la representación borgeana de esta en la figura de Otto Friedrich zur Linde. Siguiendo ideas de Susan Buck-Morss (1992) y Hal Foster (1991 y 2006), el nazismo, o mejor dicho el sujeto fascista, Otto en este caso, podría entenderse como límite negativo de la moderna subjetividad interiorizada, profundamente ascética.

Buena parte de las interpretaciones del relato desvelaron la existencia de un subtexto religioso judeocristiano que subyace a la autobiografía de Otto y concluyeron que lo deslegitimaría, y con él al nazismo, como abanderado y defensor de una nueva moral basada en la fuerza (según una lectura torticera, pero común en hasta los años cincuenta, de la filosofía de Nietzsche, sobre la que volveré al final de este artículo). La estrategia de Borges en este relato consistiría en introducir en la exposición de Otto ese subtexto judeocristiano, precisamente el mal

\footnotetext{
${ }^{3}$ Ver (además de los textos de autores ya citados de Aizenberg, Louis y López Gómez-Quiñones) Sarlo (1995) o Balderston (1996).
} 
que, según él, aquejaba al mundo: "El mundo se moría de judaísmo y de esa enfermedad del judaísmo, que es la fe de Jesús" (Obras completas I 580). Sin embargo, la vida de Otto, o el relato que hace de ella, parecería desarrollarse, involuntaria o accidentalmente, siguiendo patrones discursivos judeocristianos inconsistentes con la moral que pretende encarnar.

Repasaré brevemente algunos de estos rasgos, que la crítica ha detectado y analizado ejemplarmente, antes de ofrecer mi propia interpretación de "Deutsches Requiem". El epígrafe del relato está extraído de la Biblia, del Libro de Job: “Aunque él me quitare la vida, en él confiare" (13:15). Otto parece estar diciéndonos que se sacrifica en aras de un ideal más alto. Siempre y cuando asumamos, eso sí, que es Otto quien lo ha escogido, porque, aunque el relato es autobiográfico, incluye tres paratextos: el título, el epígrafe y cinco notas a pie de página (cuatro de ellas atribuidas en el texto a un editor). Hay, por tanto, hasta tres posibles voces en este relato: la de Otto, la de un misterioso editor y la de Borges, que en el epílogo de El Aleph se declara así su autor y nos marca la lectura al expresar cuál era su intención al escribir el texto: Entender el destino de Alemania (Obras completas I 629). La existencia de estas tres voces introduce cierta plurivocidad y problematiza enormemente el relato en primera persona de Otto. ${ }^{4}$

El caso del epígrafe bíblico, sea cual sea la voz que lo eligiera, infecta, además, el texto. La vida de Job y la de Otto coinciden: ambos aceptan un destino oscuro, sufren la destrucción de sus propiedades, la muerte de familiares e incluso el dolor físico. Ahora bien, lo hacen en orden exactamente inverso (Louis, Borges ante el fascismo 92). Job es despojado lentamente de su casa, su familia, su salud,

${ }^{4}$ El título, por ejemplo, proviene, como sabemos, de una pieza de Brahms, al que se declaran aficionados tanto Borges como Otto: Ein deutsches Requiem, pero aparece privado del artículo indefinido, lo que varía de entrada su significado. Si es Borges quien ha elegido el título, deberíamos entender el relato como un homenaje a Alemania, que habría sido sacrificada en aras de los 'bárbaros' ideales del nazismo. Ahora bien, si es Otto quien titula así su autobiografía, deberíamos interpretarlo en relación con sus ideas. Para él el sacrificio de Alemania es necesario para instaurar el régimen de la barbarie a nivel global. La obra de Brahms sería utilizada como metáfora de esta idea, ya que es un canto al triunfo sobre la muerte. El nazismo triunfaría así, como ideología y como moral bárbara, incluso sobre la propia destrucción de los nazis, o mejor dicho a causa de esta. 
mientras que Otto pierde primero la salud: es herido en 1939, en 1942 a un familiar, su hermano, y finalmente sus propiedades, su casa y su laboratorio: "mi hermano Friedrich pereció en la segunda batalla de El Alamein, en los arenales egipcios; un bombardeo aéreo, meses después, destrozó nuestra casa natal, otro, a fines de 1943, mi laboratorio" (Obras completas I 580).

Por lo demás, Louis notó que esta cita es uno de los errores más conocidos de la traducción de San Jerónimo, la Vulgata ("Besando a Judas..." 65). ${ }^{5}$ El sentido original sería: "Mira, me va a aniquilar, y no que queda ninguna esperanza; sin embargo, quiero asumir mi responsabilidad ante él / ¡Que me mate! ¡Ya no tengo esperanza! Pero en su propia cara defenderé mi conducta.” Borges seguramente conocía el error, pero ¿lo conocía Otto? Si el epígrafe es obra de Borges apunta hacia el sentido que él siempre atribuyó al texto bíblico: la imposibilidad de comprender los designios divinos y por extensión la posibilidad de descifrar el orden onto-teológico en la realidad. La manera más adecuada de afrontar esa inescrutabilidad del mundo sería, para Borges (1967), de hecho, la fantasía, lo que no implica el abandono de la realidad, sino su exploración de un modo más coherente. Para ilustrar su poder, el propio Dios habría recurrido a la fantasía en el Libro de Job al invocar a dos criaturas maravillosas cuando se dirige a Job desde la tormenta: Leviatán y Behemot.

No es esa la única alusión en el texto a la tradición judeocristiana e incluso a la islámica, que repaso brevemente para no abundar inútilmente en lo ya analizado por otros críticos. Hay al menos otros dos elementos muy llamativos: la superación del hombre viejo, una idea clave, como veremos en la subjetividad ascética. En su autobiografía no remite, sin embargo, explícitamente al superhombre de Nietzsche, sino a la religión: "Comprendí, sin embargo, que estábamos al borde de un tiempo nuevo y que ese tiempo, comparable a las épocas iniciales del Islam o del Cristianismo, exigía hombres nuevos" (Obras completas I 577). Y en esa misma línea de esforzada transformación, clave para mi propia lectura del relato,

\footnotetext{
${ }^{5}$ Louis sigue aquí el volumen de Robert Gordis (1978).
} 
encontramos una alusión a San Pablo: "batallar en Éfeso contra las fieras es menos duro (miles de mártires oscuros lo hicieron) que ser Pablo, siervo de Jesucristo; un acto es menos que todas las horas de un hombre" (Obras completas I 578). Se puede apuntar, como dato obvio, que Otto se convierte en subdirector del campo de Tarnowitz en 1941, a los 33 años, la edad a la que murió Cristo.

Además de la remisión a los ideales religiosos, deberíamos prestar atención a la forma del texto, que se asemeja al primero de los diálogos platónicos, $L a$ apología de Sócrates, cosa que no ha sido notada hasta ahora. Sócrates es el paladín del espíritu ascético anterior al judeocristianismo, a juicio de Nietzsche, que analiza su posición en La genealogía de la moral [Zur Genealogie der Moral] (1887). Otto, como Sócrates, acepta su destino, su ejecución, para no traicionar los valores que encarna. Es una clave interesante porque Borges parece ampliar el horizonte del ascetismo más allá de lo judeocristiano, como hizo el propio Nietzsche. No hay por tanto un subtexto puramente religioso, sino ascético, y esa es una clave fundamental, en mi opinión, porque el ascetismo no es terreno exclusivo de la religión, sino que ocupa un lugar destacado en la historia de la subjetividad occidental, al menos desde Sócrates.

En todo caso, la crítica interpreta el relato como la imposibilidad de pensar más allá del ideal ascético judeocristiano, y la confesión de Otto lo demostraría presentándose como un simple reflejo, invertido o subvertido, muy del gusto de Borges, de los valores de la sufriente moral del débil, que aspiraba a aniquilar. Esta es la idea que propone Vandorpe (1995), siguiendo a Alazraki (1975), quien ya notó lo irónico de introducir una cita de la Biblia en una confesión que aspira a destruir sus valores. La crítica demuestra así que existiría una estrategia mordaz de Borges, que tornaría incoherentes las ideas que Otto trata de defender, y presentaría el nazismo, en última instancia, al menos a nivel discursivo, como esa imposibilidad moral a la que se refería el argentino.

Es una lectura perfectamente válida y muy sugerente. $\mathrm{Y}$ me atrevo a aventurar que esta interpretación es muy útil porque concilia al Borges obsesionado por perversiones, subversiones, reversiones especulares en busca estetizante de una 
forma y un estilo sorprendentes y diferenciales, el Borges de la crítica canónica a la que me referí páginas atrás, con el Borges comprometido con la realidad histórica que le tocó vivir. Sigue siendo Borges, pero añadiéndole una capa de referencialidad y de compromiso político. También podría tratarse de una estrategia literaria, como señaló Louis, que analiza el texto en relación con "La última invención de Hugh Walpole” ("Besando a Judas...” 64). Borges había señalado entonces que la representación del mal no puede ser inequívoca si aspira a ser verosímil y efectiva. Lo inequívoco, sentenciaba, destruye la verosimilitud del mal, de ahí, tal vez, que Borges tratará de introducir ese subtexto religioso o ascético, que dotará de complejidad paradójica a Otto.

\section{Los riesgos del sujeto ascético y la codificación racionalista de la realidad}

La lectura en clave de paradójico ascetismo judeocristiano de Otto es tremendamente valiosa, insisto, pero pretendo desligarme de ella. Mi intención es diferente. La moral del nazismo es bien visible en Otto y se relaciona con el espíritu ascético, de corte socrático y religioso, pero también filosóficamente idealista, aunque no lo hace de manera paradójica o incongruente. Otto, sujeto fascista, representa en realidad, propongo yo, el límite negativo de la subjetividad desarrollada la Modernidad a partir del siglo XVI. Una subjetividad interiorizada que quiso cortar los vínculos entre el sujeto y el objeto, la mente y el cuerpo, lo racional y lo irracional (léase sensaciones empíricas, emociones y pasiones), e insistir en codificar el mundo desde su superioridad gnoseológica, racional y autoconsciente. Como explicó Agamben (2014), desde Sócrates en adelante, el sujeto occidental se construye desde una posición singular, trascendente, con respecto a su propio cuerpo, pero también con aquello que lo circunda, con los objetos que tiene a su disposición, e incluso con los otros. Un modelo de subjetividad que se agudizará después del momento cartesiano, como veremos, porque en ese momento se interioriza definitivamente. La complejidad de "Deutsches Requiem" reside precisamente en su habilidad para sugerir las razones filosóficas del destino de Alemania, algunas de las trazas que podrían explicar el 
surgimiento del nazismo. Índices inquietantes porque marcan en realidad la concepción de la subjetividad moderna a nivel occidental, más allá de lo puramente religioso.

Esta idea no debe parecernos extraña si pensamos que Borges señala insistentemente en su obra los peligros de toda codificación puramente racional, y nos advierte de que un acercamiento a la realidad que anule nuestra capacidad sensorial y emocional, espontánea, entraña muchos riesgos. Y esa advertencia está presente en "Deutsches Requiem", que ocupa un lugar fundamental en su obra porque es en ese relato donde muestra los terribles límites de esa subjetividad interiorizada, racionalista y profundamente ascética, en la línea de lo sugerido posteriormente por los ya mencionados Buck-Morss (1992) y Hal Foster (2006). Luego, si estoy en lo cierto, su crítica al nazismo, desde un punto de vista ideológico y moral, sería coherente con algunas de las críticas más amplias y recurrentes en su obra a cualquier forma de idealismo, y a toda ideología, que, independientemente de su grado de perversidad, es por definición una codificación idealista. Toda ideología es al fin y al cabo una opinión, que puede ser parcial o injusta, impuesta al colectivo, según explicó Mannheim (2012), que hacía derivar el término de los engañosos idola de Bacon.

El ser humano trata repetidamente de enfrentarse a la inescrutabilidad del mundo imponiéndole un orden. Lo dijo Borges de manera explícita en El idioma analítico de John Wilkins:

notoriamente no hay clasificación del universo que no sea arbitraria y conjetural. La razón es muy simple: no sabemos qué cosa es el universo [...] Cabe ir más lejos; cabe sospechar que no hay universo en el sentido orgánico, unificador, que tiene esa ambiciosa palabra. Si lo hay, falta conjeturar su propósito; falta conjeturar las palabras, las definiciones, las etimologías, las sinonimias, del secreto diccionario de Dios. (Obras completas II 86) 
Es imposible comprender el orden del mundo especialmente para la moderna subjetividad interiorizada, atrapada entre sus anhelos divinos y su simple naturaleza biológica. Desde el momento cartesiano, perdió el vínculo con un supuesto orden onto-teológico externo, "el secreto diccionario de Dios" al que alude Borges, que debía dotar de sentido al mundo, y, entre melancólico y asustado, decidió establecer un abismo entre su excepcionalidad, su conciencia como principio gnoseológico superior, y su naturaleza puramente biológica. Un lugar intermedio entre lo divino y lo animal, que no le permitía ya acceder a ese supuesto orden, o "logos óntico", en palabras de Taylor (1989). Sí lo facultaba, sin embargo, para imponer un orden puramente humano sobre la realidad, como explicita Borges en texto citado: "la imposibilidad de penetrar el esquema divino del universo no puede, sin embargo, disuadirnos de planear esquemas humanos, aunque nos conste que estos son provisorios" (Obras completas II 86).

El sujeto se refugia en su conciencia precisamente por haber perdido definitivamente la capacidad de acceder a cualquier orden trascendental exterior a él. Un proceso cuyo origen se remonta al siglo XVI, con la interiorización definitiva de la subjetividad historiada por el propio Taylor (1989), y el cambio, señalado por Rorty (1980), en la concepción de la Verdad, que pasa de hilemórfica a representacional, de externalista a internalista. El sujeto consciente, al margen ya de la divinidad o de un orden externo alcanzable, devenía desde Descartes la única base de certeza. El relativismo epistemológico se convertía así una amenaza recurrente para los modernos. Una persona, un punto de vista, y de ahí la necesidad de fortalecer un código moral neo-estoico, también interior, de conducta. Evitar el relativismo dependía de la moral, es decir, del control que ejerciéramos sobre nosotros mismos. Es decir, de un correcto uso de las emociones y las pasiones dependía la virtud de nuestro comportamiento, pero también la claridad de nuestras representaciones mentales.

Esta estrategia, que consistía en imponer un orden racional sobre la realidad, entrañaba muchos riesgos, que Borges señala insistentemente en su obra, y que tenían como base un determinado modelo de subjetividad. Por eso considero que 
en "Deutsches Requiem" Borges parece apuntar al problema de fondo, el de la subjetividad racionalista y ascética. Los humanos instrumentos de codificación, ilegítimos y arbitrarios, podían devenir, además de brutales, absolutos y autorreferenciales, y podían proliferar según sus propios códigos, aspirando a calcar o reproducir en el plano terrenal la naturaleza del Ser de Parménides, que parece una referencia ineludible para Borges. No por casualidad, el nazismo es para Otto, como el Ser para el maestro de la escuela eleática, "orbicular y perfecto" (Obras completas I 580). Una suplantación arbitraria y total de la realidad bajo la excusa de imponerle un orden del que seguramente carece por parte de un sujeto que cree poder controlar todo lo que pasa más allá de la res cogitans.

La ejemplificación de esta idea puede ser libresca en la obra de Borges, como sucede en "La biblioteca de Babel" o en "Tlön, Uqbar, Orbis Tertius". El universo es la biblioteca, compuesta de un número infinito de galerías hexagonales. No son circulares, y esto debe ser notado, porque así su forma angular permite que no haya espacio, vacío, entre ellas. El Ser de Parménides parece ser una vez más su modelo, por ser infinito e inmóvil. Si no fuera infinito, habría espacio en su exterioridad, habría no-Ser, y no sería necesariamente inmóvil. Borges critica desde bien temprano, como estaba haciendo también Curtius (1948) en esos años, por cierto, la inversión que Derrida (De la Grammatologie) llamará años más tarde: "La Fin du livre, le commencement de l'écriture". Es decir, la sustitución de la lectura en el libro de la naturaleza, la lectura de la "escritura buena", una vez que el sujeto humano interiorizado se siente ya incapaz de leer en ella un sentido trascendental, por su reproducción escritural morosa, la "escritura mala", según Derrida. Un proceso que también analizó Foucault (1966): la enciclopedia reproduce textualmente el mundo y la biblioteca organiza este universo escritural. No es de extrañar la conocida querencia por Borges del post-estructuralismo francés. Blumenberg dirá posteriormente sobre este mismo proceso que "das Geschriebene schob sich an die Stellte der Wirklichkeit, in der Funktion, sie als das endgültig Rubrizierte und Gesicherte überflüssig zu machen" (Die Lesbarkeit der Welt 17). 
Me interesa, en todo caso, el lugar de la humanidad en La biblioteca de Babel. En ese universo letrado, nos advierte Borges, corre el riesgo de desaparecer, anulada como un fantasma, subsumida por la escritura, que se desarrolla como un código opaco, autorreferencial, degenerado, completamente desligado ya del desciframiento de la realidad que pretendía operar, y que perdurará incluso cuando la única especie todavía existente, la humana, se extinga:

La escritura metódica me distrae de la presente condición de los hombres. La certidumbre de que todo está escrito nos anula o nos afantasma. Yo conozco distritos en que los jóvenes se prosternan ante los libros y besan con barbarie las páginas, pero no saben descifrar una sola letra. Las epidemias, las discordias heréticas, las peregrinaciones que inevitablemente degeneran en bandolerismo, han diezmado la población. Creo haber mencionado los suicidios, cada año más frecuentes. Quizá me engañen la vejez y el temor, pero sospecho que la especie humana - la única - está por extinguirse y que la Biblioteca perdurará: iluminada, solitaria, infinita, perfectamente inmóvil, armada de volúmenes preciosos, inútil, incorruptible, secreta. (Obras completas I 470-471)

En "Tlön, Uqbar, Orbis tertius", esos mundos librescos han sido ya capaces de generar un apéndice parasitario y apócrifo en las páginas finales de una enciclopedia. Los proyectos enciclopédicos se convierten, según Foucault (1966), en constructos lingüísticos que sustituyen el mundo según su propio orden, humano, convencional y arbitrario. Son organizadas, además, en bibliotecas, que, como la de Babel, aspiran a calcar y a suplantar espacialmente el mundo. En Borges, la textualidad de la "escritura mala" crece por sí misma. Es curioso, además, que ese siniestro desarrollo, el texto sobre Uqbar, no aparezca en una de las más reputadas reproducciones enciclopédicas del mundo: la Encyclopedia Britannica, sino en una reimpresión, una copia 'literal, pero también morosa', de esta: The Anglo-American Cyclopedia (Obras completas I 431). El artículo sobre 
Uqbar no figura en todas las copias de esa obra, cuyo tomo correspondiente consta de 917 páginas, en lugar de las 921 de la copia, única al parecer, que lo contiene. El caso de Tlön, planeta imaginario, es más impactante, ya que existe una enciclopedia completa de cuarenta volúmenes que lo describe. No se reduce a un breve texto insertado en una enciclopedia, sino que la existencia del planeta se basa es su propia descripción enciclopédica detallada. La escritura crece absurdamente no ya para suplantar el mundo, sino incluso para generar uno inexistente.

Esta estrategia proliferante se torna incluso más siniestra cuando esos mundos son capaces de trasladar sus propios objetos a nuestra realidad. Excrecencias que empezaban siendo textuales, producidas por el tejido enciclopédico, terminan por materializarse, por invadirnos también a nivel empírico. Todo sistema que trata de codificar el mundo deviene un elemento siniestro precisamente por su capacidad de crecimiento arbitrario capaz de generar incluso mundos nuevos e ignotos, parece advertir Borges. $\mathrm{Y}$ en ese sentido ha analizado "Tlön, Uqbar, Orbis tertius" y "Deutsches Requiem" Díaz Pozueta (2009), que nos habla precisamente de la manera en que el idealismo sustitutivo del mundo se transforma en ideología implantada sobre la realidad.

Porque la ideología, a su vez, es capaz de generar sus propias derivaciones, añadiría yo, y esa será la principal preocupación de Borges en relación con los germanófilos argentinos. Entender el destino de Alemania a través del sacrificio de Otto en aras del nazismo es a lo que dijo aspirar Borges, y significaba entender que este construyó una moral, y dictó una ética, por delirante que nos pueda parecer, que se puede entender como límite negativo de la interiorizada y auto-controlada de la subjetividad moderna. A esa preocupación se suma una capa puramente nacional, porque el autor señaló en el epílogo de El Aleph que "Deutsches Requiem" no es un relato para los germanos, sino para los germanófilos argentinos, que no entienden Alemania ni el nazismo, pero se esfuerzan en trasladar a Argentina este ideario. Borges no aspira a ser un intelectual universal, sino un intelectual argentino, y por eso aplica un 'filtro nacional' a su interpretación. Encontraríamos una ejemplificación literaria perfecta de este desplazamiento, y de ese 'filtro 
nacional', si comparáramos "Deutsches Requiem" con un relato escrito por Bustos Domecq (Borges y Bioy) poco después, en 1947: "La fiesta del monstruo". La codificación original del nazismo era de por sí bárbara, pero su descontextualización, su repetición por parte de los argentinos partidarios o consanguíneos del caos nazi, dirá Borges, podría ser incluso más atroz.

El desorden real, convertido afanosamente en orden humano, produce nuevos desórdenes. Los peligros degenerativos de la auto-referencialidad y la pérdida de sentido de todo código cultural es una de las claves que recorre la obra de Borges, y que encuentra su última versión, no por causalidad destructiva, en "El Congreso" (1975). Un grupo de seres humanos, tal vez temerosos de su extinción, deciden quemar los libros.

La reproducción morosa de la realidad anula la realidad. Así, la imitación prolija de la ciudad en "Del rigor en la ciencia", duplicado perfecto en tres dimensiones, ocupa exactamente el mismo espacio que la ciudad, que ya es en sí misma una organización arbitraria del espacio. Crear dos mundos iguales, ambos artificiales, indistinguibles respecto a lo que contienen, es una nueva representación de la capacidad absurdamente proliferante y paralizante de la reproducción. Ese problema se genera igualmente si es la vida del propio ser humano la que se reproduce. La memoria puramente reproductiva, la mímesis exacta, nos condena a la repetición, a un eterno retorno no específicamente nietzscheano. Uno más parecido al del revolucionario parisino Louis-Auguste Blanqui (1805-1881), basado en la repetición. Blanqui es autor de L'Éternité par les astres (1872), donde la vida de cada uno de nosotros se reproduce de manera exacta en una infinitud de planetas distintos. Repetición, eterno retorno: parálisis. Walter Benjamin parece obsesionarse por esta idea, a juzgar por la presencia de fragmentos del libro de Blanqui en el Libro de los pasajes [Passagen-Werk], que figuran, no por casualidad, en el Konvolut dedicado al aburrimiento.

Otro signo claro de esta idea tiene que ver con la función de la memoria a nivel personal. Basta pensar en "Funes, el memorioso" para entender sus riesgos cuando se apodera por completo del sujeto. No creo que sea gratuita la asociación 
entre la memoria prolija hasta el absurdo y la parálisis del personaje, que fue notada por Vitiello (2007) como alusión a Nietzsche y su intempestiva sobre la inutilidad de la historia para la vida. Esta podría remitir, además, según explica Paul de Man (1983), a la distinción schilleriana entre ingenuo y sentimental. El poeta ingenuo, explicaba Schiller (1795), está en contacto intuitivo con la realidad; el sentimental, es consciente de la escisión sujeto/objeto, y desarrolla el sentimiento de lo ingenuo como aspiración a retomar el contacto directo con la vida.

La advertencia de Borges parece afectar incluso a la propia biografía del autor, encerrado por voluntad propia en la cultura, y lamentando recurrentemente su condena: esa doble línea familiar: cultura y milicia, la pluma y la espada, que ha sido analizada por Sarlo (1995), Pauls y Helft (2000), Piglia (2001) o Williamson (2004), entre otros. Forzado a los libros por sangre paterna; fascinado por la actividad física, militar, de su rama materna. La multiplicación de sueños de cuchilleros arrabaleros le sirven de consuelo, hasta que terminan convirtiéndose ellos mismos en un sistema cultural autorreferencial de mitificaciones repetitivas absurdas. Avanzan estas más allá incluso de la propia escritura borgeana, a veces para ser corregidas, como sucede en El gaucho insufrible, de Bolaño.

La advertencia de Borges parece dirigirse, en todo caso, a la anulación de la experiencia en beneficio del pensamiento, las ideologías, la cultura, la memoria, la biblioteca, cualquier archivo, en definitiva, o imitación. Imponer un orden humano sobre la realidad inescrutable, tratar de reproducirla, repetir el tiempo o el espacio en detalle, calcar la propia identidad a través de la memoria; toda iteración, en Borges, tiende a ser prolija y de signo negativo porque atrapa al autor, al personaje o al lector en una red conceptual que nos convierte en simples cogitales y nos aleja de la experiencia directa. Pero también el acceso a un orden, a la pretendida existencia de un orden, sea trascendente o inmanente, es negativo en Borges y conduce a la muerte. Basta pensar en "El espejo y la máscara" o "La escritura del dios", donde el acceso a un código exterior a la humanidad, por comunicación 'divina', se cobra la vida de los personajes. Cada vez que la humanidad impone el velo de Maya al mundo o lo retira (o cree haberlo retirado), queda inutilizada. 


\section{"Deutsches Requiem": el ascetismo sujeto fascista}

La advertencia en "Deutsches Requiem" no es distinta. La diferencia es que ataca, insisto, el origen del problema: el desarrollo de la subjetividad moderna, interiorizada y basada en el principio gnoseológico, la conciencia racional, de organización y control de toda realidad empírica, incluido el propio cuerpo humano, las emociones y las pasiones. La obsesión de ese sujeto por comprender y controlar, por medio de la conciencia, de la razón, todo lo que escapa a ella. El movimiento era totalmente evidente ya en Descartes: dualismo ontológico (cuerpo/mente o espíritu) y ruptura óntica (ser humano/animal). La tesis de la excepcionalidad humana, estudiada y desmantelada por Schaeffer (2005 y 2007), se basa en esa distinción irreductible entre cuerpo y mente o espíritu, derivada de la concepción teológica de la subjetividad, y que separa al ser humano además del resto de seres vivos. Una mente encerrada en un cuerpo con el que no parece tener nada en común, y que debe controlar al máximo desarrollando una estrategia neo-estoica. Es la pervivencia de este principio, una vez se quiebra, o se siente como quebrada, la relación hombre / Dios, la que provoca el progresivo y peligroso aislamiento del sujeto respecto a su cuerpo, su entorno, y a su vez, el afán de organizar una realidad de origen supuestamente onto-teológico, pero que le resulta ya opaca e incomprensible.

Es relativamente sencillo notar hasta qué punto Otto responde a este modelo de subjetividad, basado en la ilusión de control sobre la propia vida y el propio cuerpo por medio del ascetismo, y que encuentra en el sujeto fascista su curiosa y negativa apoteosis. En Otto veremos no solo la representación de una subjetividad auto-contenida, empeñada en controlar sus pasiones y emociones, sino también un sujeto empeñado en determinar su origen, un sujeto auto-fundado o auto-genético, y su finalidad, Homo telos. Estos tres elementos están estrechamente relacionados. De hecho, la subjetividad auto-fundada y auto-dotada de una finalidad es incomprensible sin esa auto-contención extrema. 
En su figuración autobiográfica, Otto se presenta de inicio como un proyecto de guerrero. Y lo hace aduciendo su genealogía, a tres de sus ancestros, militares, para reforzar la idea de un destino común marcado de manera externa, es decir, por su tradición familiar. Un antepasado, Christoph zur Linde, su bisabuelo, Ulrich Forkel, y su padre, Dietrich zur Linde. Los tres perecieron en hechos de armas en guerras muy relevantes para Alemania: la Guerra de los Siete Años, la Franco-prusiana y la Gran guerra. Su hermano Friedrich, también militar, muere en 1942, en la segunda batalla de El Alamein, según nos dirá más adelante. Otto será fusilado, sin embargo, por torturador y asesino. La perversión parece completa. Otto representaría la imagen contrahecha de la nobleza y el valor guerreros. Pero esta conclusión es en realidad equívoca. Otto pretende alcanzar las características del guerrero de una manera bastante más compleja.

Por qué aducir el destino guerrero como justificación vital. Cuáles son esas características a las que quiere acogerse. Sin obviar el contexto bélico del relato, podríamos encontrar una clave en la filosofía de Kant, que es el primer gran ejemplo filosófico germano de subjetividad interiorizada, depurada de emociones y sentimientos. En su Crítica de la razón práctica [Kritik der praktischen Vernunft] [1788]), que trata de demostrar la existencia de una moral universal, los sentidos han perdido toda función, pese a que en la Crítica de la razón pura [Kritik der reinen Vernunft] $[1781,1787]$ ) eran fuente ineludible de conocimiento. El ser moral, auto-causado y espontáneo, debe estar libre de toda contaminación sensorial. La vida queda, por lo tanto, sacrificada a la idea: en términos kantianos, la necesidad se supedita a la libertad, porque el imperativo categórico es, todavía entonces, como el ser moral, inaccesible a los sentidos.

La interiorización de los sentidos es todavía visible en la Crítica del juicio [Kritik der Urteilskraft] (1790), pese a que tratará esta de restaurar la cesura entre libertad y necesidad, que lo es entre el sujeto trascendental y su sensibilidad, precisamente a través de la conducta estética, que es sensorial. En la tercera Crítica Kant discute el concepto de lo sublime y la reacción de terror frente a lo inconmensurable, motivada por nuestro instinto de auto-conservación. Señala 
entonces que, si observamos el espectáculo de la inmensidad incontrolable desde un lugar seguro, tomaremos conciencia de nuestra propia grandeza. El control de los sentidos y las emociones nos hace superiores. Y Kant termina relacionando el ideal del autocontrol precisamente con la disciplinada figura del guerrero, el militar, insensible a cualquier riesgo señalado por los sentidos e imperturbable a las emociones, y capaz, por ello, de actuar con rectitud y eficacia en su entorno. El guerrero parece ser la mejor ejemplificación del sujeto trascendental kantiano teorizado en la segunda Crítica, un sujeto que debe estar libre de toda sensación y emoción que pueda poner en riesgo su autonomía, no solo porque lo relacionan ineluctablemente con el mundo, sino también porque lo convierten en un ser pasivo, inactivo, que reacciona a los estímulos exteriores y a emociones 'incontrolables' como la alegría, la tristeza, la piedad o el deseo.

La remisión de Otto al destino guerrero puede, por tanto, tener una base filosófica, y está relacionada con el control de los sentidos y las emociones. Sin embargo, el editor apunta en nota que la personalidad más célebre de su familia es en realidad un teólogo: Johannes Forkel (1799-1846), "que aplicó la dialéctica de Hegel a la cristología" (Obras completas I 576). Esta es una clave que podría despistarnos fácilmente, porque tendemos a identificar ascetismo con religiosidad judeocristiana, pero, de acuerdo con Kant, no sería el religioso, sino el guerrero, el prototipo perfecto de sujeto activo, moralmente libre de la necesidad y depurado de lo sensorial.

Otto señala, sin embargo, que carece de "toda vocación de violencia" (Obras completas I 577), y además se siente inclinado hacia tareas intelectuales. También recalca que por entonces se detenía maravillado, "trémulo de ternura y gratitud" (Obras completas I 577), con la infinita variedad del mundo de Brahms, autor precisamente del "Deutsches Requiem" al que alude el título, y Shakespeare. Ternura y gratitud parecen palabras clave porque aluden claramente a la aguda emocionalidad de Otto, completamente alejada de las cualidades del guerrero kantiano, de las cualidades que él quería encarnar por herencia familiar. Me parece interesante relacionar esta doble clave genealógica de Otto, armas y letras, con la 
doble herencia borgeana, y la 'condena' de ambos a las letras en detrimento de las armas. Las concomitancias entre ambos llegan a ser incómodas, pese a la firme posición antinazi de Borges.

Pese a estas limitaciones, Otto quiere proseguir el digno destino familiar y se involucra en un acto guerrero, o al menos violento. Participa en los disturbios de Tilsit en marzo de 1939. Detrás de una sinagoga recibe entonces dos balazos. La escaramuza fue al parecer tan nimia que "los diarios no la registraron" (Obras completas I 577), apunta tristemente. Sin embargo, marca completamente el devenir del nazi. Las dos heridas de bala le ocasionaron la amputación de una pierna, y el editor apunta además en nota: "Se murmura que las consecuencias de esa herida fueron muy graves" (Obras completas I 578). ¿Más graves que la amputación de una pierna, se pregunta el lector? ¿Tan graves que no se dicen abiertamente, sino que solo se murmuran? Otto añade enigmáticamente: "Símbolo de mi vano destino, dormía en el reborde de la ventana un gato enorme y fofo" (Obras completas I 578). El secretismo y la gravedad parecen sugerir que las heridas también inutilizaron sexualmente a Otto. Y son precisamente esas repercusiones las que lo obligan a virar su rumbo vital, en realidad, a reinventarse, a auto-fundarse.

Con una sola pierna y sexualmente inhabilitado, y todo ello de manera accidental mientras trataba de ajustarse a las características del ideal guerrero, Otto expresa su anhelo de acomodarse a un modelo auto-genético de subjetividad, y lo hace desechando toda justificación divina del destino humano: "Aseveran los teólogos que si la atención del Señor se desviara un solo segundo de mi derecha mano que escribe, esta recaería en la nada, como si la fulminara un fuego sin luz" (I 578). Le acomoda mejor la opinión de Schopenhauer, aunque podemos inferir que no termina de creérsela:

En el primer volumen de Parerga und paralipomena releí que todos los hechos que pueden ocurrirle a un hombre, desde el instante de su nacimiento hasta el de su muerte, han sido prefijados por él. Así, toda 
negligencia es deliberada, todo casual encuentro una cita, toda humillación una penitencia, todo fracaso una misteriosa victoria, toda muerte un suicidio. No hay consuelo más hábil que el pensamiento de que hemos elegido nuestras desdichas; esa teleología individual nos revela un orden secreto y prodigiosamente nos confunde con la divinidad. (Obras completas I 578)

El proceso de auto-génesis tendrá una meta precisa, que está necesariamente relacionada con la depuración de las pasiones y las emociones. Esa 'teleología individual', presentada en realidad como consuelo, parece regir su figuración autobiográfica. Otto se someterá a un durísimo ejercicio de ascesis, de depuración de lo sensorial y lo afectivo, con el objetivo de convertirse en sujeto activo, moralmente activo, es decir, libre de afectos. Para recalcar la dificultad del proceso, ya nos ha indicado su vocación por el arte y su escasa vocación violenta. La profunda ironía del relato gira en torno a la aparente voluntad de Otto de acomodarse conscientemente a un determinado modelo de subjetividad ascética, que a menudo es dubitativa, y que el lector entiende en realidad como fruto de diversas situaciones que escapan por completo a su control, como los balazos en Tilsit. En definitiva, Otto ha terminado por entender que uno de los grandes peligros para el sujeto es precisamente sucumbir ante las emociones, porque, supuestamente, nos debilitan, nos vuelven pasivos, y no nos permiten entender y codificar el mundo racionalmente, no nos permiten controlarlo, y sobre todo no nos permiten actuar libre y activamente, es decir, moralmente, porque, para Otto, el nazismo es intrínsecamente una moral que necesita de un hombre nuevo.

Autogénesis y autocontención están ligadas en realidad desde los inicios de la filosofía occidental, precisamente en el ascetismo socrático que había denunciado Nietzsche en Zur Genealogie der Moral (1887). Como estudiaron Foucault (2001) y posteriormente Agamben (2014), los aforismos socráticos 'conócete a ti mismo' (gnōthi seauton) y 'cuida de ti mismo' (epimelia heautou) estaban necesariamente relacionados. El acceso a la Verdad, al Bien y a la Belleza, exteriores al sujeto en 
la filosofía platónica, era un proceso gnoseológico que dependía del control, el cuidado, que ejerciéramos sobre nuestras impresiones, pasiones y pulsiones. Foucault llama a este proceso 'espiritualidad':

On appellera alors «spiritualité »l'ensemble de ces recherches, les pratiques et expériences que peuvent être les purifications, les ascèses, les renoncements, les conversions du regard, les modifications d'existence, etc., qui constituent, non pas pour la connaissance, mais pour le sujet, pour l'être même du sujet, le prix à payer pour avoir accès à la vérité. (L'Herméneutique du sujet 16-17)

El sujeto no tenía derecho a alcanzar la verdad por un simple ejercicio cognitivo; debía cambiar, debía devenir otro que sí mismo, y ahí está ya enunciada la clave que marca el devenir de Otto:

Car tel qu'il est, il n'est pas capable de vérité. Je crois que c'est là la formule la plus simple, mais la plus fondamentale, par laquelle on peut définir la spiritualité. Ce qui entraîne pour conséquence ceci : que, de ce point de vue, on ne peut pas avoir de vérité sans une conversion ou sans une transformation du sujet. (L'Herméneutique du sujet 16)

La necesaria transformación tomaba dos vías: ascesis (askēsis) y amor (erōs). La ascesis, ligada a la auto-contención, nos permitiría refundarnos o generarnos de nuevo, y poder elevarnos para contemplar el reino de las ideas. El amor, en cambio, nos ilumina sin esfuerzo. Otto optará decididamente por la primera vía, convirtiéndose en un sujeto profundamente ascético, en coherencia con la evolución de la filosofía occidental.

Foucault, en relación con la búsqueda de la Verdad, nos habla de hecho de una evolución filosófica de la subjetividad en tres fases: memorística (Platón), 
meditativa (San Agustín) y metódica (Descartes). Señala un cambio radical para la última, porque el interiorizado sujeto de conocimiento devendría un problema fundamental. Como sabemos, los cursos de Foucault se centran en Platón, neoplatónicos y estoicos, fundamentalmente, así que es difícil averiguar a qué se refería exactamente cuando habló de un cambio radical. Debemos conformarnos con la equiparación que hace en los cursos entre la espiritualidad o purificación en busca de la verdad y el principio gnoseológico. Es decir, el principio gnoseológico se fundiría con la espiritualidad a partir de Descartes.

El problema al que seguramente se refiere Foucault es la interiorización definitiva de la subjetividad en el momento cartesiano, que provocaba que el sujeto consciente, al margen ya de la divinidad o de un orden externo alcanzable, fuera la única base de certeza. El relativismo epistemológico se convertía una amenaza recurrente para los modernos. Una persona, un punto de vista, de ahí la necesidad de fortalecer un código moral neo-estoico, también interior, de conducta. Evitar el relativismo dependía, una vez más, de la moral, es decir, del control que ejerciéramos sobre nosotros mismos. Es decir, de un correcto uso de las emociones y las pasiones dependía la virtud de nuestro comportamiento, pero también la claridad de nuestras representaciones mentales. Epistemología y moral, principio gnoseológico y espiritualidad, volvían a estar ligadas, aunque de manera algo más compleja.

No solo la filosofía de autores como Descartes y Kant, sino también la evolución de la estética moderna responde a esta obsesión por controlar el cuerpo como vía de acceso a la Verdad y al Bien. El cuerpo parecía ser un enemigo, un incómodo mecanismo que debíamos regular en nuestro periplo epistemológico y moral, dos aspectos que se presentan siempre relacionados. Aisthetikós remite etimológicamente a la experiencia sensorial de la percepción. Deriva de aisthánesthai y traducido significa aproximadamente: percibir con los sentidos. En 1750 Baumgarten escribe el que se considera primer tratado moderno sobre el tema, y la entiende todavía según esta acepción: la define como scientia cognitionis sensitivae, pero añade que es una scientia inferioris, una 'ciencia inferior', 
precisamente por estar relacionada con los sentidos. Sus órganos: ojos, piel, oído, nariz y boca, constituyen el límite entre el interior y el exterior. Se trata de un límite pre-lógico y pre-lingüístico, y por lo tanto previo al sentido y a la representación mental de las realidades con las que contacta. La función de esa 'ciencia inferior' es ejercer como filtro entre el desorganizado flujo de la realidad y la mente. La estética moderna, o sus órganos, empieza a dibujarse como una prótesis gracias a la cual la razón puede lidiar con el flujo heraclíteo del mundo, según la expresión que Eagleton (The Ideology of the Aesthetic 18) toma de Husserl.

Conocimiento y control vuelven a aparecer ligados. La concepción estética moderna es resultado lógico del tipo de sujeto que la experimenta, la concibe y la teoriza. La relación con la espiritualidad, tal y como la definía genealógicamente Foucault es evidente. El sujeto, el hombre nuevo al que aspira a convertirse Otto, es un sujeto capaz de controlar su cuerpo, lo que sucede a su alrededor y dotarse a sí mismo y a lo que sucede a su alrededor, de una finalidad: Homo telos. Un modelo que Buck-Morss (1992) definió como sujeto 'anestesiado', al tiempo que señalaba la utilidad política de esta subjetividad insensible relacionándola con los avances médicos del XIX en el campo de la anestesia médica. Un sujeto impasible, un médico o un estadista, puede operar con más eficiencia sobre un cuerpo, físico o social, también anestesiado física o simbólicamente, sea para estudiarlo, sanarlo o modelarlo de acuerdo con un ideal. No me parece gratuito que Buck-Morss (1992) apunte que la ilusión extrema de control, de autocontención, es desarrollada normalmente por hombres, probablemente como Otto, castrados, real o simbólicamente, ya que los genitales son el mayor índice de irracionalidad e imprevisibilidad en su cuerpo.

La idea clave sobre las que se basa la autobiografía de Otto es precisamente la fundación del hombre nuevo, activo, que controla su destino, y ello pasa por el control de uno mismo, por el cuidado de uno mismo. El proceso de Otto debe pasar por una durísima ascesis. Se somete a ella a raíz de ser nombrado subdirector del campo de Tarnowitz en 1941. Lo hará entonces porque es un campo de concentración donde podrá poner a prueba su capacidad para controlar sus 
emociones, para depurarse de ellas. Querrá asegurarse de que es un sujeto activo que rige su propia vida, aunque su mayor índice de auto-contención física, la castración, haya sido accidental. Decide ponerse a prueba, inmunizarse, en los calabozos de Tarnowitz, donde debe afrontar y no cometer el mayor pecado: la piedad. El nazi se esfuerza por lidiar y superar el 'riesgo' de ser presa de las emociones, de comportarse pasivamente. E insiste en la idea de devenir otro que sí mismo, que es la ascesis definitiva, más difícil de conseguir para el piadoso, el misericordioso, aquel que, como él, respondía a la emoción estética que le procuraban Brahms o Shakespeare temblando de ternura. Su acción, parece querer decirnos, aunque sea una perversión, es en realidad más esforzada que la del guerrero, que se sitúa en un contexto bélico. Él es carcelero y debe afrontar el dolor ajeno de manera íntima sin inmutarse:

El ejercicio de ese cargo no me fue grato; pero no pequé nunca de negligencia. El cobarde se prueba entre las espadas; el misericordioso, el piadoso, busca el examen de las cárceles y del dolor ajeno. El nazismo, intrínsecamente, es un hecho moral, un despojarse del viejo hombre, que está viciado, para vestir el nuevo. En la batalla esa mutación es común, entre el clamor de las capitanes y el vocerío; no así en un torpe calabozo, donde nos tienta con antiguas ternuras la insidiosa piedad. No en vano escribo esa palabra; la piedad por el hombre superior es el último pecado de Zarathustra. Casi lo cometí (lo confieso) cuando nos remitieron de Breslau al insigne poeta David Jerusalem. (Obras completas I 578)

Otto se esfuerza por destruir cualquier índice pasional o emocional, y, sobre todo, en explicárnoslo. Lo hace a través de la figura de David Jerusalem. De nuevo un ataque a los judíos, un ataque al otro, es el que puede procurar la depuración definitiva, según su visión, aunque de nuevo el resultado final perseguido, la aniquilación del poeta, no parece ser fruto de su acción directa. "Fui severo con él; no permití que me ablandaran ni la compasión ni su gloria” (Obras completas I 
579), nos dice significativamente. Jerusalem 'había consagrado su genio a cantar la felicidad' (I 578), y él propio Otto reconoce errónea su equiparación con Whitman, porque "Whitman celebra el universo de un modo previo, general, casi indiferente" (Obras completas I 578); en cambio, "Jerusalem se alegra de cada cosa, con minucioso amor. No comete jamás enumeraciones, catálogos" (Obras completas I 579). El poeta judío parece centrarse, curiosamente, en lo inmediato, en la celebración de la vida individualizada, evitando toda estrategia literaria que lo aleje de ella.

Parece responder, todavía, al sentido original moderno de la experiencia estética, antes de que fuera instrumentalizada como herramienta de control del sujeto interiorizado. La Aesthetica de Baumgarten empezó a señalar lo que estaba en juego en la emergencia de la estética como rama independiente, aunque inferior, de la filosofía. Baumgarten descree de las tradiciones racionalistas del XVIII y señalan la importancia de la inmediatez de la relación sensorial con el mundo, de la que es parte el placer estético. Celebra todavía la multiplicidad de la particularidad sensorial, ya que cada elemento tiene su significado en un todo todavía garantizado por la divinidad. Es precisamente ese impulso intuitivo, directo y vital, lo que Otto quiere destruir. No es difícil concluir, a estas alturas, que Jerusalem, cuya existencia niega en nota el editor, es en realidad la parte sensorial y emocional del propio Otto; de hecho, parece desprenderse de sus propias palabras: "Ignoro si Jesusalem comprendió que si yo lo destruí, fue para destruir mi piedad. Ante mis ojos, no era un hombre, ni siquiera un judío; se había transformado en el símbolo de una detestada zona de mi alma. Yo agonicé con él, yo morí con él, yo de algún modo me he perdido con él; por eso, fui implacable" (Obras completas I 579).

Es su eliminación la que parece permitir a Otto equipararse definitivamente a la definición del guerrero kantiano, ascético por antonomasia, que debe destruir toda inclinación emocional, especialmente la piedad. Aunque Otto se ha visto obligado a hacerlo de manera mucho más trabajosa. No será capaz de matarlo, por cierto (ya sabemos que carece de vocación violenta), pero sí de inducirlo al suicidio, 
según nos dice. Lo consigue aplicándole precisamente un régimen de ascetismo completo y forzándolo a cortar su vínculo con la realidad inmediata. Ese régimen, tal vez no nos sorprenda en un relato de Borges, está basado en la memoria, en la sustitución de la realidad: "Yo había comprendido hace muchos años que no hay cosa en el mundo que no sea germen de un Infierno posible; un rostro, una palabra, una brújula, un aviso de cigarrillos, podrían enloquecer a una persona, si ésta no lograra olvidarlos. ¿No estaría loco un hombre que continuamente se figurara el mapa de Hungría?" (Obras completas I 579).

Borges parece remitir aquí a dos de sus textos de la época, ya mencionados en este artículo: "Funes, el memorioso" (1944) y "Del rigor en la ciencia" (1946). La reproducción morosa de la realidad, e incluso de los propios recuerdos, corta los lazos con el mundo y desplaza por completo la identidad humana. Como señaló Díaz Pozueta en el artículo citado, Borges estaba más cerca del idealismo de Hume, un empirista, que de la filosofía idealista de Berkeley (2009 209). Y me parece importante añadir que para el escocés la identidad del sujeto humano se basa precisamente en la percepción de la realidad: "I never can catch myself at any time without a perception and never can observe anything but the perception" ( $A$ Treatise of Human Nature 〔355-356). Cortado el lazo entre sujeto y percepción, su identidad, sencillamente, se desvanece, y la locura y la muerte lo acechan. Otto concluye así su obra personal de construcción de la subjetividad, extremando el ascetismo que la recorre a lo largo de la Modernidad, especialmente en la filosofía alemana clásica. Y es profundamente irónico pensar que, más allá de subvertir el modelo ascético en el que la crítica lo ha visto atrapado, se ajusta accidentalmente a este modelo de purificación idealista que engloba también el ascetismo judeocristiano, pero responde a una moral más amplia y constante en Occidente a lo largo de los siglos.

\section{Conclusiones}

Detectar la presencia de un subtexto moral ascético, judeocristiano, en la confesión de Otto, como hizo buena parte de la crítica, parecía resaltar una 
incoherencia que invalidaba su postura. Yo sugiero que el problema es más amplio y apunta a la subjetividad interiorizada, en la que lo epistémico y lo moral se relacionan estrechamente, y conduce a un ascetismo que hunde sus raíces en la filosofía antigua, y de cuya moral habría bebido también el judeocristianismo y la filosofía idealista posterior, como denunció el propio Nietzsche.

El propio Borges era ya consciente en los años cuarenta de la simplificación torticera a la que había sido sometida por el nazismo la obra del prusiano. ${ }^{6}$ Lo que Nietzsche denunciaba era precisamente la presencia de una subjetividad ascética que se había apoderado de la filosofía moral occidental desde Sócrates en adelante. Nunca se trató, para él, de anular la moral del débil, cuya genealogía traza, e imponer la moral violenta del fuerte, basada en la manipulación de la voluntad de poder, como supuestamente habría teorizado en La voluntad de poder [Der Wille zur Macht] un libro inexistente como tal, fruto de la manipulación de sus ideas por parte de su hermana, Elizabeth Förster-Nietzsche. Se trataba, en realidad, para Nietzsche, de minar todo sistema moral, de débiles o fuertes, que cortara el vínculo con la realidad inmediata, con el cuerpo. Se trataba, como dirá Zaratustra, de atacar en su base a los despreciadores del cuerpo, fueran griegos, romanos, judíos, cristianos, estoicos o idealistas en Asi habló Zaratustra. Un libro para todos y para nadie [Also sprach Zarathustra. Ein Buch für Alle und Keinen] (1883). Nietzsche, el Nietzsche real, habría atacado igualmente el ascetismo depurado del sujeto fascista, como atacó el antisemitismo o el nacionalismo racial.

Porque Nietzsche fue curiosamente el primer gran filósofo alemán que se opuso a este modelo. El ascetismo implicaba la negación de la vida física en nombre de un código de valores, una moral, trascendente al individuo y que este debía esforzarse en alcanzar. Podía tener sentido en esas dos primeras fases de la hermenéutica de la subjetividad de las que nos hablaba Foucault: la memorística (ligada a la condición inmortal del alma en Platón) y la meditativa (ligada fundamentalmente a la vida eterna prometida por el cristianismo). Existía, o mejor

${ }^{6}$ Un gran mérito de Borges, porque Nietzsche solo fue editado correctamente a partir de 1958 por los italianos Giorgio Colli y Mazzino Montinari. 
dicho, se creía entonces en la existencia de un código de valores estable y externo al sujeto, un logos óntico, que este debía alcanzar en su ejercicio de espiritualización, de ahí la necesidad de purificarse. Nietzsche hablará de nihilismo, precisamente porque esta estrategia consistía en negar la realidad inmediata, la vida, en nombre de un código de valores trascendental e invisible. Una idea con la que sospecho que Borges estaría muy de acuerdo. La subjetividad interiorizada (la fase metódica, según Foucault) ha perdido contacto con la posibilidad de acceder a toda ordenación trascendental, y la ha sustituido por un código puramente humano. No varía, pues, el comportamiento, el modelo de construcción de la subjetividad, pero ya no existe un orden externo que alcanzar. Es, para Nietzsche, la segunda fase del nihilismo, todavía más absurda que la primera. Deleuze lo explicó meridianamente:

Toute à l'heure, on dépréciait la vie du haut des valeurs supérieures, on la niait au nom de ces valeurs. Ici, au contraire, on reste seul avec la vie, mais cette vie est encore la vie dépréciée, qui se poursuit maintenant dans un monde sans valeurs, dénué de sens et de but, roulant toujours plus loin vers son propre néant. Toute à l'heure, on opposait l'essence à l'apparence, on faisait de la vie une apparence. Maintenant on nie l'essence, mais on garde l'apparence: tout n'est qu'apparence, cette vie qui nous reste est restée pour elle-même apparence. (Nietzsche et la philosophie 170)

El nazismo, al menos en su concepción de la subjetividad, puede entenderse de acuerdo con esta línea de evolución del pensamiento occidental, respecto a la que Nietzsche se muestra completamente ajeno, en realidad. Se sigue negando la vida, el contacto inmediato con la realidad, pero ahora en nombre de un constructo puramente humano, una ideología. Y Borges seguramente lo sabía. En Algunos pareceres de Nietzsche, un artículo publicado en La Nación el 11 de febrero de 1940, se preocupaba por señalar la injusticia de considerar su obra un "evangelio para matones", y aducía una serie de fragmentos que desmentían por completo su imagen de nacionalista alemán antisemita y bárbaro. Borges, en realidad, si 
observamos algunas de las ideas generales que recorren su obra, parece estar de acuerdo con la premisa fundamental del prusiano: la verdad, lo que asumimos como verdadera representación del mundo, es a menudo un simple constructo humano, arbitrario y autorreferencial que no nos permite tener un contacto pleno con la vida.

\section{Bibliografía}

Agamben, Giorgio. L'uso dei corpi. Homo sacer IV/2. Venezia: Neri Pozza, 2014. Aizenberg, Edna. Aleph Weaver: Biblical, Kabbalistic and Judaic Elements in Borges. Potomac, MD: Scripta Humanistica, 1984.

. "Postmodern or Post-Auschwitz. Borges and the Limits of Representation." Variaciones Borges 3 (1997): 141-52.

. "'Nazism is Uninhabitable': Borges, the Holocaust, and the Expansion of Knowledge." Jorge Luis Borges: Thought and Knowledge in the XXth Century, edited by Alfonso de Toro y Fernando de Toro. Madrid Frankfurt am Main: Iberoamericana | Vervuert, 1999. 255-61.

. "Deutsches Requiem" Variaciones Borges 20 (2005): 33-57.

Alazraki, Jaime. Versiones, inversiones, reversiones. El espejo como modelo estructural del relato en los cuentos de Borges. Madrid: Gredos, 1975.

Balderston, Daniel. ¿Fuera de contexto? Referencialidad histórica y expresión de la realidad en Borges. Rosario: Beatriz Viterbo, 1996.

Barrenechea, Ana María. La expresión de la irrealidad en la obra de Jorge Luis Borges. México: Colegio de México, 1957.

Baumgarten, Alexander Gottlieb. Aesthetica. 1750. Hildesheim: Georg Olms, 1961.

Benjamin, Walter. Das Passagen-Werk. Hrg. Rolf Tiedemann. Frankfurt am Main: Suhrkamp, 1982.

Blumenberg, Hans. Die Lesbarkeit der Welt. Frankfurt am Main: Suhrkamp, 1981. 
Borges, Jorge Luis. Conferencias. Buenos Aires: Instituto de Intercambio Cultural y Científico Argentino-Israelí, 1967.

. Obras completas, edición de Carlos V. Frías, 3 vols. Buenos Aires: Emecé, 1989.

Botul, Jean-Baptiste. La Vie sexuelle d'Emmanuel Kant. Paris: Mille et une nuits, 1999.

Buck-Morss, Susan. “Aesthetics and Anesthetics: Walter Benjamin's Artwork Essay Reconsidered." October 62 (1992): 3-41.

Bürger, Peter. Zur Kritik der idealistischen Ästhetik. Frankfurt am Main: Suhrkamp, 1983.

Curtius, Ernst Robert. Europäische Literatur und lateinisches Mittelalter. Bern: A. Francke, 1948.

Deleuze, Gilles. Nietzsche et la philosophie. 1962. Paris: PUF, 1973.

De Man, Paul. “A Modern Master.” The New York Review of Books 3.7 (1964) https://www.nybooks.com/articles/1964/11/19/a-modern-master/ . Blindness and Insight: Essays in the Rhetoric of Contemporary Criticism. Minneapolis, MN: U of Minnesota P, 1983.

Derrida, Jacques. De la grammatologie. Paris: Les Éditions de Minuit, 1967.

Díaz Pozueta, María. "From Philosophical Idealism to Political Ideology in 'Tlön, Uqbar, Orbis Tertius' and 'Deutsches Requiem'." The New Centennial Review 9.3 (2009): 205-228.

Eagleton, Terry. The Ideology of the Aesthetic. London: Basil Blackwell, 1990.

Fichte, Johann Gottlieb. Einige Vorlesungen über die Bestimmung des Gelehrten / Algunas lecciones sobre el destino del sabio. 1794. Ed. bilingüe de Faustino Oncina Coves y Manuel Ramos Valera. Madrid: Istmo, 2002.

Foster, Hal. Prosthetic Gods. Cambridge, MA, MIT P, 2006.

Foucault, Michel. Les Mots et les choses. Une archéologie des sciences humaines. Paris: Gallimard, 1966. . L'Herméneutique du sujet. Paris: Gallimard, 2001.

Gordis, Robert. The Book of Job. Commentary, New Translations and Special 
Studies. New York: The Jewish Theological Seminary of America, 1978. Gutiérrez Girardot, Rafael. Insistencias. Barcelona: Ariel, 1998.

Hume, David. A Treatise of Human Nature. 1739-1740. Edited by David F. Norton and Mary J. Norton. Oxford, UK: Oxford UP, 2007.

Kant, Immanuel. Kritik der reinen Vernunft. 1781, 1787. Werkausgabe, B. III y IV. Frankfurt am Main: Suhrkamp, 1968. . Kritik der praktischen Vernunft. 1788. Werkausgabe, B. VII. Frankfurt am Main: Suhrkamp, 1968.

. Kritik der Urteilskraft. 1790. Werkausgabe, B. X. Frankfurt am Main: Suhrkamp, 1968.

Lawrence, Ramsey. "Religious Subtext and Narrative Structure in Borges' Deutsches Requiem." Variaciones Borges 10 (2000): 119-138.

López Gómez-Quiñones. Borges y el nazismo (Sur: 1927-1946). Granada: U de Granada, 2004.

Louis, Annick. "Besando a Judas. Notas en torno a Deutsches Requiem”. Jorge Luis Borges. Intervenciones sobre pensamiento y literatura. Ed. William Rowe, Claudio Canaparo y Annick Louis. Barcelona: Paidós, 2000. 6171.

. Borges ante el fascismo. Bern: Peter Lang, 2007.

Nietzsche, Friedrich. "Vom Nutzen und Nachteil der Historie für das Leben”. 1873. Unzeitgemäße Betrachtungen. München: Goldmann, 1999. . Also sprach Zarathustra: ein Buch für alle und keinen. 1883. Berlin: Insel, 1976.

. Zur Genealogie der Moral. Hrg. Otfried Höffe. 1887. Berlin: Akademie, 2004

Pauls, Alan y Helft, Nicolás. El factor Borges. México: FCE, 2000.

Pezzoni, Enrique. Enrique Pezzoni: lector de Borges. Buenos Aires: Sudamericana, 1999.

Piglia, Ricardo. Crítica y ficción.Barcelona: Anagrama, 2001. 
Rodríguez Monegal, Emir. "Borges y la política." Revista Iberoamericana 100 (1977): 269-91.

Rorty, Richard. Philosophy and the Mirror of Nature. Princeton, NJ: Princeton UP, 1980.

Sarlo, Beatriz. Borges. Un escritor en las orillas. Barcelona: Ariel, 1995.

Schaeffer, Jean-Marie. "La Thèse de l'exception humaine." Communications 78 (2005): 189-209. . La Fin de l'exception humaine. Paris: Gallimard, 2007.

Schiller, Friedrich. Über naive und sentimentalische Dichtung. 1795. Hrg. Klaus L. Berghahn. Leipzig: Philipp Reclam, 2001.

Sebald, Winfried Georg. Luftkrieg und Literatur: Mit einem Essay zu Alfred Andersch. München: Hanser, 1999.

Taylor, Charles. The Sources of the Self. The Making of Modern Identity. Cambridge, MA: Harvard UP, 1989.

Vandorpe, Yasmine-Sigride. "Ironie et paradoxe dans Deutsches Requiem de Jorge Luis Borges". La Littérature des camps: la quête d'une parole juste, entre silence et bavardage. Études rassemblées et présentées par Vincent Engel. Louvain-la-Neuve: Université catholique de Louvain, 1995. 81-93.

Vitiello, Vincenzo. Borges, memoria y lenguaje. Madrid: Círculo de Bellas Artes, 2007.

Williamson, Edwin. Borges. A Life. London: Penguin, 2004. 